\title{
Approaching Eden: Adam and Eve in Popular Culture, by Theresa Sanders
}

Lanham: Rowman \& Littlefield, $2009 \mid x i+245$ pages | ISBN: 978-0-7425-6333-9 (hardback) $\$ 37.50$

Interest in how the Bible has been received in various contexts and genres has spiked in the past few years, giving rise to several excellent monographs, edited

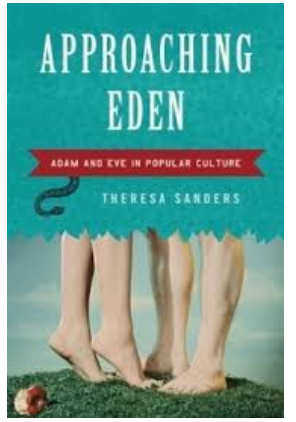
works, and even an entire commentary series (the Blackwell Bible Commentary) devoted to examining these "receptions." In this intriguing work, Theresa Sanders focuses on one specific biblical text, Gen 2-3, and tracks how its ideas, implications, and inferences have been enacted, engaged, and examined by a range of readers and media within "popular culture."

Due to the sheer scope of such a project, Sanders wisely limits her inquiry to "both widely distributed and widely recognized" examples of "popular culture" in the "past hundred years" that make a "recognizable reference" to Gen 2-3 (vii-x). In her first chapter, she tries to makes clear what seems to be the main point of the book, noting, "the cultural memory of the story [in Genesis] frequently differs — sometimes quite dramatically — from the story as it is found in the Bible" (2). Also, the goal of the book is stated obviously on pages 9-Io: “This book hopes to make sense of this bewildering array [of later references to Gen 2-3] by giving background about the history of Jewish and Christian interpretations of the story, and then by showing how these interpretations find new life in popular culture."

Sanders introduces the reader to a range of critical issues in the study of Genesis, including whether it can/should be read as (a) history or myth; (b) a divinely-revealed or historically-contextualized document; (c) one story or 
two; (d) the product of more than one author/source; and (e) a text that is fundamentally about the past, present, future, or all three. In doing so, she notes several times that how one answers these questions is not as important as being aware of the reasons behind various answers, as well as the implication(s) of those answers ( $15, \mathrm{I} 7$, and 27). While this whirlwind tour of critical scholarship on Genesis is not likely to nourish the seasoned scholar, it does inculcate the neophyte with enough of an academic context to understand the claims in the remainder of the text.

In her third chapter, Sanders begins her discussion of popular-cultural renderings of Gen $2-3$ by examining "issues of sex and gender," with the goal of "showing how they are influenced by the story of Adam and Eve and how they manifest themselves in popular culture" (33). To this end, she begins with a brief yet helpful section on sex and gender (33-35), prior to formulating several basic questions on page 35 . This organizational clarity could be helpful, although the six issues that she addresses in the remainder of the chapter are not obviously tied to the way in which she states these questions. Also, as I will note later, this seeming organizational clarity is not thoroughgoing in the book. Nonetheless, her approach in this chapter is paradigmatic for what follows. For example, in her section titled "You're Evil Like Eve," Sanders begins with the oft-heard assumption that since Eve was evil, all subsequent women are evil as well. After addressing the biblical text briefly, she moves on to consider the survival of this trope in western art before examining three specific films in more depth, including The Lady Eve, All About Eve, and Second Time Lucky. Her analyses of these films are, by necessity, cursory, but certainly detailed enough to make her point, i.e., "The spare description of these acts in [Gen 3:6] has been elaborated upon and embellished by commentators, artists, and poets in ways that perhaps tell us more about the interpreters than it does about the story itself" (44).

The remainder of the chapters follows much the same pattern, i.e., a focus on one specific issue, the identification of several key questions/points about that issue, and an examination of the way(s) in which specific popular cultural examples interpret the Genesis story regarding those questions/points. For example, in her fourth chapter ("Fig Leaves"), her discussion centers on the issues of sex, marriage, and same-sex relations, and she marshals numerous examples from the history of scriptural interpretation and film to assess how these issues have been treated.

Chapters 5 and 6 are of a piece, as they both examine the ways in which the "curses," or punishments of Adam and Eve respectively have been under- 
stood by later interpreters. In the former chapter, Sanders scrutinizes Gen 2: 17 , i.e., "the relation between Adam's disobedience and death ... to see how religious traditions regarding this 'curse' have shaped popular culture" (9I). In what follows, she posits four different interpretations of 2:17 from both scholars and popular culture, before concluding with an examination of how "popular culture warns against the quest for immortality" (I07). The "curse" that Sanders examines in chapter 6 has to do with menstruation, childbirth, and virginity. This chapter is noteworthy for its extended treatment of Mary as an "antidote" of sorts to the activity and inheritance of Eve (I I 8-27).

In chapter 7, Sanders shifts her focus to the impact Gen 2-3 has had on modern scientific understandings of our history as a species, focusing specifically on evolutionary theory and containing a particularly helpful rumination on the I960 film Inherit the Wind. The remainder of this chapter examines creationism, Intelligent Design, the 2004 trial in Dover, PA, an episode from the seventeenth season of The Simpsons, and The Creation Museum in Kentucky. In analyzing these topics, Sanders covers a large amount of territory admirably and accessibly. Her eighth chapter-which focuses on nudity, simplicity, and innocence (55) — addresses topics ranging from a distrust of technology, religious nudism, vegetarianism, and ecological issues related to animals and land.

Sanders's last two chapters, much like chapters 5 and 6, hang together nicely, examining as they do utopian movements and interpretations of Genesis found in science fiction. Chapter 9 spends several pages discussing specific utopian groups in North America prior to returning to popular culture products such as Lois Lowry's The Giver and Gary Ross's film Pleasantville. The tenth chapter, not surprisingly, begins with a consideration of an episode from Star Trek: The Original Series before probing such varied examples as Star Trek V: The Final Frontier, Margaret Atwood's novel The Handmaid's Tale, and the Pixar film Wall-E. At the end of this chapter, Sanders provides a brief conclusion to the entire book (2 IO-I2).

Even though I found Sanders's work to be well-researched and accessible, I was puzzled and, at times, troubled by several issues. First, even though her book is focused on "popular culture," she spends less than two pages defining that term in her Preface, and, more troublingly, allows her discussion of its definition to be introduced and framed by Wikipedia. Given the proliferative plurality and multiple manifestations of popular culture, a more serious discussion would have been more useful. Along with this definitional difficulty, I was disappointed by the lack of a standard organization in the sense 
that there was a great variance amongst her chapters regarding the presence of a clear thesis, goal(s), and/or conclusion(s). To be sure, some chapters include a clear thesis and/or goal (chapters 3, 5, and 8), and some contain clear conclusions (chapters 2, 4, 8, and Io). However, more uniformity in the organization of the chapters would increase the accessibility or obviousness of her discussions, especially to lay readers in an educational setting. Third, like many scholars who engage popular culture, Sanders includes a multitude of examples. Sometimes these connections are not only on-point, but historically illuminating (not to mention entertaining), such as her discussion of the 1937 radio play in which Mae West voiced the character of Eve (64-70). Sometimes, though, the connections between issues in the biblical text and the examples from popular culture she examines seem to me to be only tangentially related. This was especially obvious in chapter 5, in which Eve's Bayou, Young Adam, and Death Becomes Her simply did not have enough points of contact in my opinion to be included as examples worthy of discussion under a separate subheading.

Fourth, I was puzzled at what, exactly, is the point of the book. That is, Sanders states several times what she sees as "the purpose of the book," e.g., "to give readers some insight into the history of interpretations of the Genesis story and to enable them to make sense of the bewildering array of allusions to it" (2 I I). So, is her purpose simply informative, rather than argumentative? Is there no central claim behind the book as a whole? She remarks at the end of chapter 2 that, "This book does not seek to persuade readers to one position or the other on any of the issues discussed above. Instead, it lays out the options and, more importantly, shows exactly what is at stake in each" (30). Again, if Sanders's goal is simply to catalog various examples of how popular culture has adapted or alluded to Gen 2-3, then what is the significance of her contribution? In asking this question, I do not mean to imply that Sanders's work has no merit; it obviously does. What I mean is that Sanders needed to make the significance of her work much clearer to the reader by buttressing statements about the "purpose" of the book with (a) how her analysis fulfills that purpose; (b) how it advances our understanding of Gen 2-3; and (c) how it contributes to an increased understanding of the reciprocal relationship between Bible and popular culture. In my opinion, her work accomplishes all three of these goals, but it does not state this accomplishment clearly or specifically.

Finally, the issue of significance is tied to a fifth and final issue, viz., is Sanders performing a "History of Interpretation" or a "Reception History" 
analysis? That is, is she concerned with how key scriptural interpreters, like Paul or Augustine, have understood Gen 2-3? Or, does her analysis examine broader targets such as television, film, and popular fiction? Does she address the impact texts like Gen $2-3$ have had on various groups or ideologies, or is she more interested in identifying specific themes and tracking how they develop in time? I ask these questions because Sanders does not, and this seeming unawareness of these important distinctions hampers her ability to situate her work within a tradition of inquiry (such as the Blackwell Bible Commentary series I mention above). Having said this, my feeling is that Sanders would identify readily with a Reception History emphasis, especially given her claim that "Whether we believe that Genesis describes what really happened a long time ago, or that it is a myth expressing a religious worldview, the story and our interpretations of it tell us how we think life 'ought' to be" (90). This concern with the impact of Gen 2-3, how it affects flesh-and-blood readers and their beliefs and actions, accords nicely with the emphases of Reception History.

In sum, Sanders's work is often fascinating and always suggestive in how it illuminates the connections between Gen 2-3 and popular cultural products. And if I cannot unreservedly recommend it for the reasons listed above, I will certainly return to it often and look forward to her future work.

Dan W. Clanton

Doane College 